\title{
The Help of Hypnodontics to a Patient With Scleroderma
}

\author{
Mohsen Ramazani $^{1, *}$; Nafiseh Zarenejad ${ }^{2}$; Kaveh Ebrahimi ${ }^{3}$ \\ ${ }^{1}$ Department of Endodontics, School of Dentistry, Mazandaran University of Medical Sciences, Sari, IR Iran \\ Department of Endodontics, School of Dentistry, Mazandaran University of Medical Sciences, Sari, IR Iran
2Department of Restorative Dentistry, School of Dentistry, Mazandaran University of Medical Sciences, Sari, IR Iran \\ 3 Department of Restorative Dentistry, School of Dentistry, Mazandaran University of Medical Sciences, Sari, IR
${ }^{2}$ epartment of Prosthodontics, School of Dentistry, Mazandaran University of Medical Sciences, Sari, IR Iran \\ ${ }^{*}$ Corresponding author: Mohsen Ramazani, Department of Endodontics, School of Dentistry, Mazandaran University of Medical Sciences, Sari, IR Iran. Tel: +98-9153257658, E-mail: \\ m.ramazani@mazums.ac.ir
}

Received: June 21, 2014; Revised: December 13, 2014; Accepted: January 29, 2015

\begin{abstract}
Introduction: Scleroderma, or systemic sclerosis, is a chronic connective tissue disease generally classified as one of the autoimmune rheumatic diseases

Case Presentation: A58-year-old woman was informed of her scleroderma, while receiving oral prosthetic rehabilitation. Mouth opening limitation had unfortunately led to treatment interruption. The psychological load of the disease itself, along with dental treatment cessation, resulted in patient's disappointment and social separation. Three hypnosis sessions were conducted for normalizing patient's psychological status primarily, and for the facilitation of dental treatment, as well. The range of mouth opening changed from 3.7 to $6.2 \mathrm{~cm}$, allowing for easier entrance of dental appliances into the mouth for completion of prosthetic rehabilitation. With the tooth prostheses in place, the patient gained more social confidence and started sharing her experience with other patients with the same condition.

Discussion: This case illustrates that hypnosis therapy may prove beneficial for patients with limited mouth opening secondary to scleroderma, facilitating the prosthetic rehabilitation programs for both dental specialists and patients, with a secondary important impact on the patient's social perception of himself.
\end{abstract}

Keywords: Hypnodontics; Mouth Opening Limitation; Psychological; Scleroderma

\section{Introduction}

Scleroderma, or systemic sclerosis, is a chronic connective tissue disease generally classified as one of the autoimmune rheumatic diseases. The word "scleroderma" comes from two Greek words: "sclero" meaning hard, and "derma" meaning skin (1-3). Hardening of the skin is one of the most visible manifestations of the disease. Internal organs are also frequently affected with the systemic form.

People with scleroderma often have specific facial changes. The nose appears pinched and thinned and the opening of the mouth might be decreased in size ("microstomia" or "small mouth"). Often, the skin over the upper lip can become lined. The development of dilated small blood vessels, called telangiectasia, affects the face and other parts of the body. The appearance of the eyes can also alter, all of which can negatively impact the patient's appearance (4). The general tightening of the skin over the face makes lip and mouth movements, as well as oral hygiene, difficult. Microstomia may make it difficult to open the mouth wide enough for dental procedures or even oral hygiene. Therefore, preventative dental care through regular flossing and brushing of the teeth and gums after each meal is of utmost importance (5). The best approach to management is by means of facial grimacing and mouth stretching exercises, performed daily.
Regular dental visits are also important to help prevent dental caries. The dentist can also recommend a personalized program of good oral hygiene. Floss holders, pump toothpaste tubes, and built-up handles on toothbrushes can help people with hand impairment, while an electric toothbrush is strongly advised (6).

From the psychological aspect, a common reaction to being told that one has a disease such as scleroderma is, "why me?" It is not clear why only several people develop the disease and others do not. One does not bring scleroderma upon him or herself, and therefore, should not feel guilty or responsible for the illness. A person newly diagnosed with scleroderma may feel alone and uncertain about where to turn for help (7). Psychopatologically speaking, the majority of the sclerodermatic patients may manifest mild anxiety due to apprehension and vigilance related to the perceived threat from the illness and the uncertainties over etiology, prognosis and outcome. Others may show depression, generally of moderate severity. He, or she, may experience a number of other feelings and emotional reactions from time to time, including initial shock or disbelief, fear, anger, denial, self-blame, guilt, grief, sadness, somatization, profound feelings of generalized hostility, and interpersonal sensitivity, which may be due to the gradual disfigurement

Copyright (C) 2015, Mazandaran University of Medical Sciences. This is an open-access article distributed under the terms of the Creative Commons Attribution-NonCommercial 4.0 International License (http://creativecommons.org/licenses/by-nc/4.0/) which permits copy and redistribute the material just in noncommercial usages, provided the original work is properly cited. 
resulted from skin thickening. The severity of illness, and consequent disability, could be regarded as the central factors contributing to the development of the psychiatric symptomatology. Paranoid ideation and psychoticism of the sclerodermatic patients probably reflect a vulnerability towards the manifestation of more serious, psychotic, psychopathology. Medication should not be regarded as indifferent in this cumulus of psychological anxiety triggers $(7,8)$.

Family members may experience similar feelings. Feelings, in themselves, are neither good nor bad; one simply "has" them. Sharing them with family members and friends, or with others who have had the same experiences, can be helpful $(1,4)$. Other factors, such as social support, may also play significant roles (8). Professional counseling can also help people with scleroderma and their family members who are having difficulty coping with their feelings. Instead of "scleroderma patient", the term "person with scleroderma" should better be used. The person with scleroderma may be a "patient" in the doctor's office, hospital or clinic, but he or she is much more than that. Thinking of oneself as a total person, with a full life, may help to cope with scleroderma and enable one to maintain a positive, and also realistic insight (9). Rebuilding thoughts is the key step for such conditions (3).

Hypnosis is defined as an attentive, receptive, focal concentration, with diminished peripheral awareness. Hypnotizability, expectancies, motivation, absorptive capacity/fantasy proneness, and attitudes towards hypnosis are five psychological factors most frequently mentioned as important. The rapport (also referred to as "resonance" and "harmony") and social context are identified as social factors.

Evidence supports the usefulness of hypnotic treatments, to address biological, psychological and social factors, and their interactions in any medical condition. The biopsychosocial model of hypnosis can help in understanding complex issues, such as scleroderma. Importantly, this model allows the possibility for multiple factors to play a role and contribute to hypnotic responding (10).

\section{Case Presentation}

While receiving dental services for prosthetic rehabilitation, our 58-year-old patient referred to dermatologist just because of limitation of mouth opening, which is essential for the optimal performance of dental treatment. A comprehensive battery of tests revealed that she was suffering from Scleroderma. This was a major turning point, because both the oral prosthetic service, and also several other aspects of her and her family life, got affected. Therefore, we changed our plan from a regular somatic to a more comprehensive biopsychological approach. The first measure implied in the management of this case was to conducting a team work, including an endodontist who has been trained as an advanced hypnotherapist, a restorative dentistand also prosthodontist for dental treatments. Although, at first, five sessions were preplanned to complete whole levels of treatment, fortunately, prior to commencing the fourth session, treatment finished convincingly with optimal results. As a first step, a simple interview was performed to see if there is the potential for a hypnosis intervention. Simultaneously, and also during pre-talk, several myths in which the patients believed concerning hypnosis, were corrected. The Spiegel biological scale of the patient scored as 3 out of 5. At the first one-hour session, all activity had been targeted just for relaxation, anxiety management, attitude correction about the new encountered unusual somatic condition, correction of coping skills for new life, increasing self-confidence, and, eventually, conditioning with light folkloric music and also, her very kind mother's name. Two-week intervals were considered between all three hypnosis sessions. During the second hypnosis session, which lasted 50 minutes, she was fallen more easily and more deeply into trance, using the conditioning keys and suggested specially for her dental treatment procedure, particularly useful cooperation with the dentist to gain suitable results. Meanwhile, her attitude about her new facial appearance and the others' reactions were repaired. Surprisingly, less pain and discomfort would have been felt thereafter, due to any joint movement throughout the body, especially in case of the shoulder and temporomandibular joints. The third session, lasting for 40 minutes, was spent for reinforcement of previous inductions and conditions, and a new induction was performed for increasing the intention to help the other persons newly and unexpectedly faced with disturbing conditions, such as scleroderma, or any other. Prior to the fourth session, she obtained satisfactory psychological capabilities again, and hence, no need was felt for continuing hypnotic interventions urgently. All the pre-desired dental treatments were delivered to the subject, and she was also asked to use hypnosis any time needed. Three follow up visits showed no relapse, although the disease itself had its ongoing nature. Nevertheless, it was not detrimental psychologically, since the subject had learnt new copping skills for such circumstances, emphasizing that the hypnotic inductions and treatments must be promising and real, as well. Additionally, from that time on, the subject herself did explain the benefits of hypnosis for the others in the society.

\section{Discussion}

Participating actively in one's own healthcare is of prime importance to the person with scleroderma. It is equally important to cooperate and communicate effectively with the doctor who is managing the disease. While these two the person with scleroderma and the doctor, are the focal point of the management "team", multiple other individuals and resources can be enlisted to form a health and support network (2).

Several skin conditions are well appreciated to resonate with the individual's mental climate. Among them, there 
is scleroderma, which is sensitive to psychological pressures and possessing recognized immunological components. Using hypnosis, both somatic and psychological elements of scleroderma can be covered and influenced by appropriate suggestions (4).

Regarding the facts mentioned, our hypnotic intervention could effectively cover the complex issues related to the patient with scleroderma: somatically, to provide a suitable situation for conduction of dental treatments, and psychologically, to return the patient to an acceptable level of expectation, and acceptation. This case report hopefully lightened the missed, yet necessary chain of actions required the in treatment of any psychosomatic impairment.

\section{Authors' Contributions}

Mohsen Ramazani, was solely responsible for the conception and design of the study. Mohsen Ramazani and Kaveh Ebrahimi collected the clinical data and interpreted them. Mohsen Ramazani, Nafiseh Zarenejad and Kaveh Ebrahimi, drafted the manuscript and together they read and approved the final manuscript.

\section{Financial Disclosure}

All authors declare that there is no financial disclosure.

\section{Declaration of interest}

None Declared.

\section{References}

1. Alantar A, Cabane J, Hachulla E, Princ G, Ginisty D, Hassin M, et al. Sorel M, Maman L, Pilat A, Mouthon L. Recommendations for the care of oral involvement in patients with systemic sclerosis. Arthritis Care Res (Hoboken). 2011;63(8):1126-33.

2. Albilia JB, Lam DK, Blanas N, Clokie CM, Sandor GK. Small mouths ... Big problems? A review of scleroderma and its oral health implications.J Can Dent Assoc. 2007;73(9):831-6.

3. Andrick JM. Cultivating a "chairside manner": dental hypnosis, patient management psychology, and the origins of behavioral dentistry in America, 1890-1910. J Hist Behav Sci. 2013;49(3):235-58.

4. Amin K, Clarke A, Sivakumar B, Puri A, Fox Z, Brough V, et al. Denton CP, Peter EM, Butler P. The psychological impact of facial changes in scleroderma. Psychol Health Med. 2011;16(3):304-12.

5. al-Hadi LA. A simplified technique for prosthetic treatment of microstomia in a patient with scleroderma: a case report. Quintessence Int. 1994;25(8):531-3.

6. Chu $\mathrm{CH}$, Yeung CM, Lai IA, Leung WK, Mok MY. Oral health of Chinese people with systemic sclerosis. Clin Oral Investig. 2011;15(6):931-9.

7. Angelopoulos NV, Drosos AA, Moutsopoulos HM. Psychiatric symptoms associated with scleroderma. Psychother Psychosom. 2001;70(3):145-50.

8. Thombs BD, Jewett LR, Kwakkenbos L, Hudson M, Baron M, the Canadian Scleroderma Research G. Major Depression Diagnoses are Often Transient among Patients with Systemic Sclerosis: Baseline and 1-Month Follow-up. Arthritis Care Res (Hoboken). 2014.

9. Comstedt LR, Svensson A, Troilius A. Improvement of microstomia in scleroderma after intense pulsed light: A case series of four patients. J Cosmet Laser Ther. 2012;14(2):102-6.

10. Jensen MP, Adachi T, Tome-Pires C, Lee J, Osman ZJ, Miro J. Mechanisms of hypnosis: toward the development of a biopsychosocial model. Int J Clin Exp Hypn. 2015;63(1):34-75. 